\title{
Diabetic Retinopathy Analysis
}

\author{
R. Sivakumar, ${ }^{1 *}$ G. Ravindran, ${ }^{1}$ M. Muthayya, ${ }^{2}$ S. Lakshminarayanan, ${ }^{2}$ \\ and C. U. Velmurughendran ${ }^{2}$ \\ ${ }^{1}$ Centre for Medical Electronics, College of Engineering, Guindy, Anna University, Chennai-600 025, India \\ ${ }^{2}$ Sri Ramachandra Medical College \& Research Institute, Porur, Chennai-600 116, India
}

Received 2 October 2003; revised 13 June 2004; accepted 22 August 2004

\begin{abstract}
Diabetic retinopathy is one of the common complications of diabetes. Unfortunately, in many cases the patient is not aware of any symptoms until it is too late for effective treatment. Through analysis of evoked potential response of the retina, the optical nerve, and the optical brain center, a way will be paved for early diagnosis of diabetic retinopathy and prognosis during the treatment process. In this paper, we present an artificial-neural-network-based method to classify diabetic retinopathy subjects according to changes in visual evoked potential spectral components and an anatomically realistic computer model of the human eye under normal and retinopathy conditions in a virtual environment using 3D Max Studio and Windows Movie Maker.
\end{abstract}

\section{INTRODUCTION}

Diabetic retinopathy is a common cause of visual loss in the world and it is a potentially blinding complication of diabetes that damages the eye's retina $[1,2,3,4$, $5,6,7,8,9,10,11,12,13]$. Non-insulin-dependent diabetes mellitus (NIDDM) may be the most rapidly growing chronic disease in the world. Its long-term complications, including retinopathy, nephropathy, neuropathy, and accelerated macrovascular disease, cause major morbidity and mortality $[14,15,16,17]$. At first, you may notice no changes in your vision. But do not let diabetic retinopathy fool you. It could get worse over the years and threaten your good vision. Diabetic retinopathy is a complication of diabetes that affects the blood vessels of the retina [18]. Growth of new blood vessels, known as proliferative retinopathy, may lead to blindness through hemorrhage and scarring. A deterioration of retinal blood vessels causing loss of blood vessels and leakage into the retina is known as maculopathy and leads to visual impairment and may progress to blindness.

Electrophysiological tests reveal an abnormal function of the visual system in patients with diabetic retinopathy [19]. Visual evoked potential (VEP) has been used in the clinical environment as a diagnostic tool for a long time $[20,21,22]$. VEP is one of the noninvasive tools in analyzing diabetic retinopathy $[23,24,25]$. So far not much of the work has been taken up to identify the effect of retinopathy on optical response and variation in the functioning of the optic nerve [26]. Through analysis of evoked potential response of the optical nerve and optical brain center a way will be paved for early diagnosis of diabetic retinopathy and prognosis during the treatment process [27, 28, 29, 30, 31, 32, 33, 34].

In general, the clinical use of VEP is based on the peak amplitude and the latencies of the N75, P100, and N145 [22, 35, 36, 37]. The amplitude and the latencies of these peaks are measured directly from the signal $[38,39]$. This requires precise definition of the starting and the end points. Latency measure depends on the point at which the latency is calculated and usually irregular peaks occur due to background EEG, so that averaging and interpolation are required. Therefore the diagnosis based on amplitude and latency in time domain is not alone sufficient. Hence other components should also be taken into consideration. In recent years, many researchers have described a variety of approaches to extract the evoked potentials from the background ongoing EEG [40, 41, 42, 43, 44, 45, 46, 47]. The investigation of the frequency domain characteristics of VEP is an attractive analytic approach because it allows detection of subtle waveform abnormalities that may escape detection with normal latency measurements $[48,49,50]$. The spectral analysis of VEP can yield useful information when it is performed carefully $[51,52,53,54,55,56,57,58,59,60]$.

Classification of the severity of diabetic retinopathy and quantification of diabetic changes are vital for assessing the therapies and risk factors for this frequent complication of diabetes. Current clinical studies use the standardized, validated Wisconsin grading system of retinopathy, which is performed by an experienced ophthalmologist or grader using standard photographs. This method 
is a time-consuming process which requires significant training and exercise and is vulnerable to observer error $[61,62,63]$.

The artificial neural network (ANN) has been used in a number of different ways in medicine and medically related fields $[64,65,66,67,68]$. The principle advantages of ANNs are that they are able to generalize, adapting to signal distortion and noise without loss of robustness, and that they are trained by example and do not require precise description of patterns to be classified or criteria for classification $[62,69,70]$. Computer simulation is well established as a powerful and effective way of modeling health care systems $[63,70,71]$.

In our analysis, we first present a method to classify diabetic retinopathy subjects according to changes in VEP spectral components using feedforward ANN. Second we present an anatomically realistic computer model of the human eye under normal and retinopathy conditions in a virtual environment using 3D Max Studio and Windows Movie Maker.

\section{MATERIALS AND METHODS}

\section{Subjects}

Experiments were carried out with 50 normal and 300 abnormal subjects (135 females and 165 males in the age group of 39-65 years). The subjects were obtained from the diabetic department with duration of diabetics and type of diabetics, that is, insulin-dependent diabetes mellitus (IDDM) and NIDDM. Only NIDDM patients were taken to further analysis. After papillary dilation the subjects were screened in the ophthalmology department with both direct and indirect ophthalmoscopy, further vision test, and refraction test, and intraocular pressure was measured. High intraocular pressure subjects were eliminated from further analysis. The NIDDM subjects were divided based on ophthalmoscope results into 4 groups: first group is control (normal) and the other 3 groups have diabetic retinopathy - second group, background diabetic retinopathy (BDR), third group, preproliferative diabetic retinopathy (PDR) and fourth group, proliferative diabetic retinopathy (PPDR).

\section{VEP recordings}

All the VEP recordings were performed in a specially equipped electrodiagnostic procedure room in the neurology department (darkened, sound-attenuated room). At the beginning, the patient is seated comfortably approximately 1 meter away from the pattern-shift screen and the viewing distance adjusted based on the subject's visual acuity. The visual stimuli were checkerboard patterns (contrast 70\%, mean luminance $110 \mathrm{~cd} / \mathrm{m}^{2}$ ) generated on a TV monitor and reversed in contrast at the rate of two reversals per second. At the viewing distance of $114 \mathrm{~cm}$ the check edges subtended 15 minutes of visual angle and the screen of the monitor subtended $12.5^{\circ}$. The refraction of all subjects was corrected for the viewing dis-

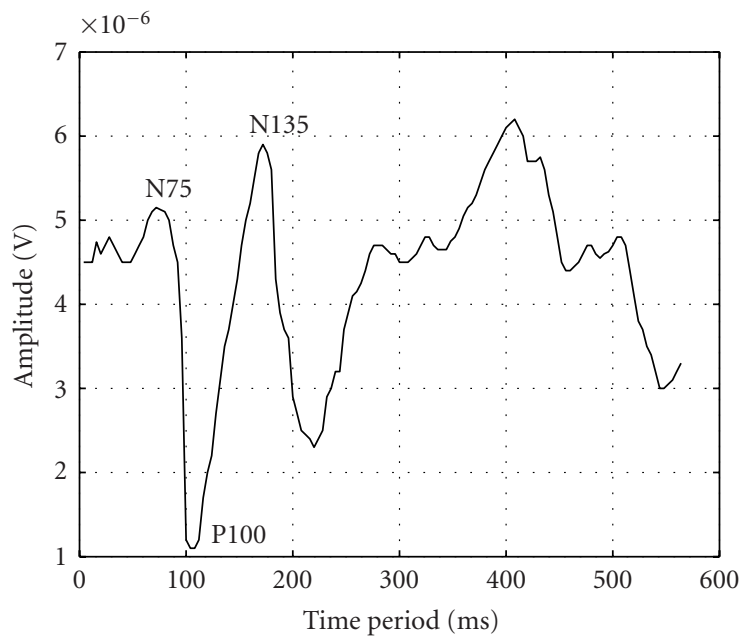

FIgURE 1. Normal subject VEP waveform.

tance. The stimulation was monocular, with occlusion of the contralateral eye.

Standard silver-silver chloride disc surface electrodes were fixed in the following positions: active electrode at $\mathrm{Oz}$, reference electrode at Fpz, ground on the left ear (according to the international 10/20 electrode system). The interelectrode resistance was kept below $3 \mathrm{k} \Omega$. The bioelectric signal was amplified (gain 20000 ), filtered (bandpass, $1-100 \mathrm{~Hz}$ ), and averaged (200 events free from artifacts were averaged for every trial) with sweep speed $50 \mathrm{~ms} /$ div and sensitivity $2 \mu \mathrm{v} /$ div using Nicolet Viking IV NT machine. The analysis time was 500-millisecond intervals following a stimulus.

\section{VEP data analysis}

The recorded averaged VEP data appears as a waveform with characteristics points N75, P100, and N135 shown in Figure 1 with potential on the vertical axis ( $\mathrm{Y}$ component) and time on the horizontal axis (X component). The analogue signal was digitized at a sampling rate of 1024 samples/s. Using Welch's averaged periodogram method the spectral components of the sampled data were identified using MATLAB signal processing toolbox functions with 95\% confidence level.

\section{Feature extraction and classification}

First, two dominant peaks' amplitude and corresponding frequency values in the spectrum were extracted. Correlation between the spectral components and diabetic retinopathy stages was identified. These VEP features are classified by feedforward neural network into normal, BDR, PPDR, and PDR categories.

\section{Neural network configuration}

We implemented the three-layer feedforward backpropagation neural networks, that is, one input layer, one hidden layer, and one output layer. The ANN had 6 input nodes, 4 hidden nodes, and 4 output nodes. The four 


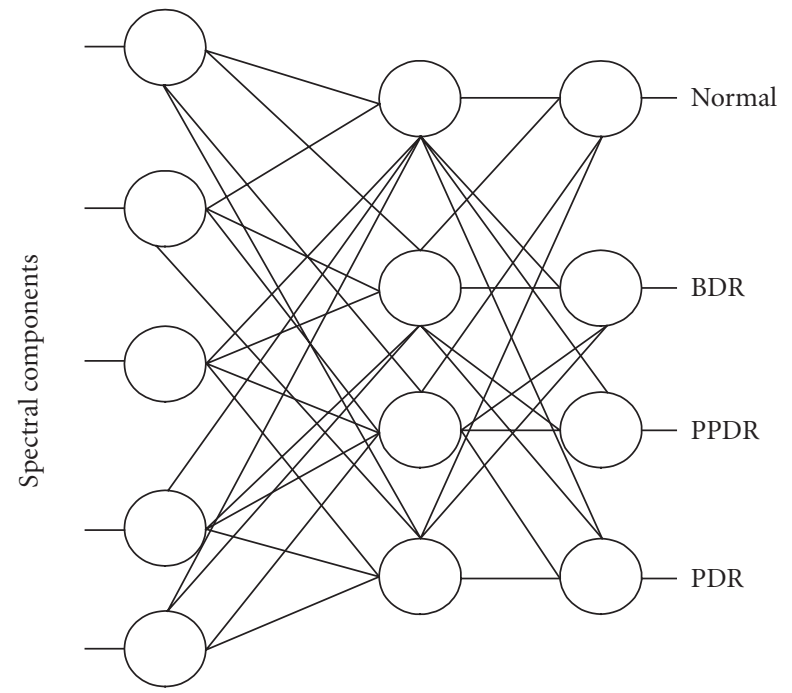

FIGURE 2. Feedforward neural network.

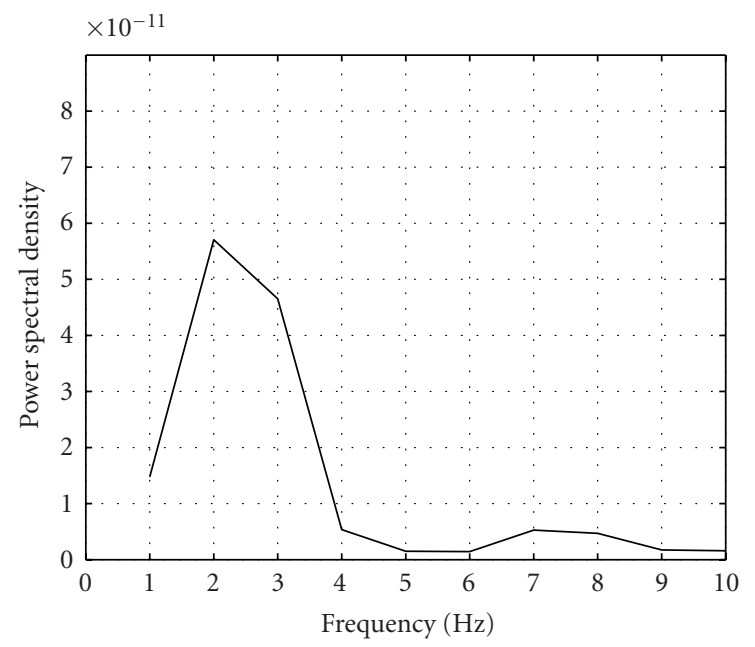

Figure 3. Normal subject VEP spectrum.

output nodes corresponded to normal waveform, BDR waveform, PPDR waveform, and PDR waveform. The neural network output vector is based on the VEP spectral components (Figure 2).

\section{Neural network training}

The neural networks were trained by backpropagation algorithm. Gradient descent (GDM) was used to minimize the mean squared error between network output and the actual error rate. During the training period we utilized 6 input nodes, 6 hidden nodes, and 4 output nodes, logsin transfer function, GDM training method, 6000 epochs, 0.9 learning rate, 0.0001 goal. The training error continues to decrease as the number of epochs increases. Repeated experiments were performed to determine the size of the hidden layer and training sample.

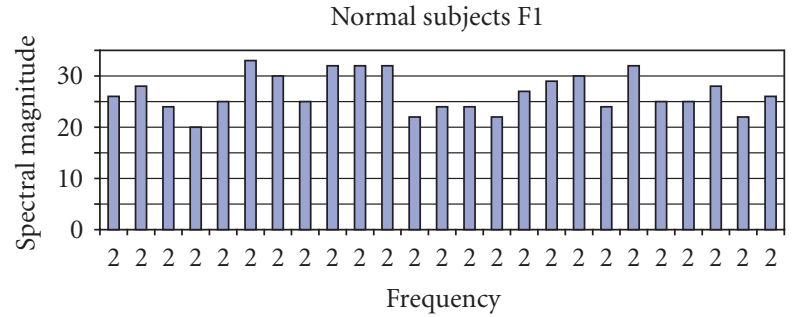

FIGURE 4. 25 normal patients' first spectral component 2D histogram.

Our final ANN consists of 4 hidden units, which provide a compromise between the mapping error and the computational time. Weights were initialized to random values and networks were run until at least one of the following termination conditions was satisfied:

(1) maximum epoch,

(2) minimum gradient,

(3) performance goal.

\section{Neural network testing}

For testing, the input data was presented to the ANN without weight adjustment. The output of the ANN was compared with the clinician's classification based on the retinal blood vessel examination and VEP averaging latency methods. Results were compared, and the percent of input patterns, which was correctly classified, was calculated.

\section{RESULTS}

\section{VEP spectral components interpretation}

The spectral response results show that the peak response occurs at specific frequencies like 2, 3, 4, 5, and $6 \mathrm{~Hz}$. The first two spectral components with considerable amplitude were extracted from the power spectrum plot. The important finding of this result shows that there are distinct differences at the peak frequencies for normal and diabetic retinopathy patients. Positive correlation was obtained between the spectral components with the disease condition $(r=0.987)$.

It is found that in all 50 normal subjects the dominant spectral component falls exactly at $2 \mathrm{~Hz}$ and the second dominant peak falls in the range of $4-7 \mathrm{~Hz}(P<.0001)$. Figure 3 shows the spectral plot of normal subject. It is shown that the dominant spectral component falls at $2 \mathrm{~Hz}$ and the secondary component at $7 \mathrm{~Hz}$. 25 normal subjects' dominant spectral component magnitudes 2D histogram is presented in Figure 4 and the corresponding second dominant peak magnitude values are presented in Figure 5.

It is found that for all the BDR subjects the dominant spectral peak falls in the range of $2-3 \mathrm{~Hz}$ and the second dominant peak falls in the range of $5-9 \mathrm{~Hz}(P<$ $.0001)$. Figure 6 shows the spectral plot of BDR subject. 


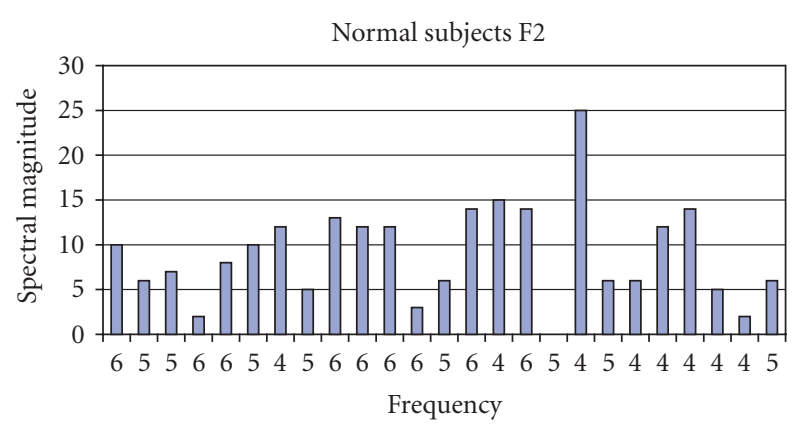

FIGURE 5. 25 normal patients' second spectral component 2D histogram.

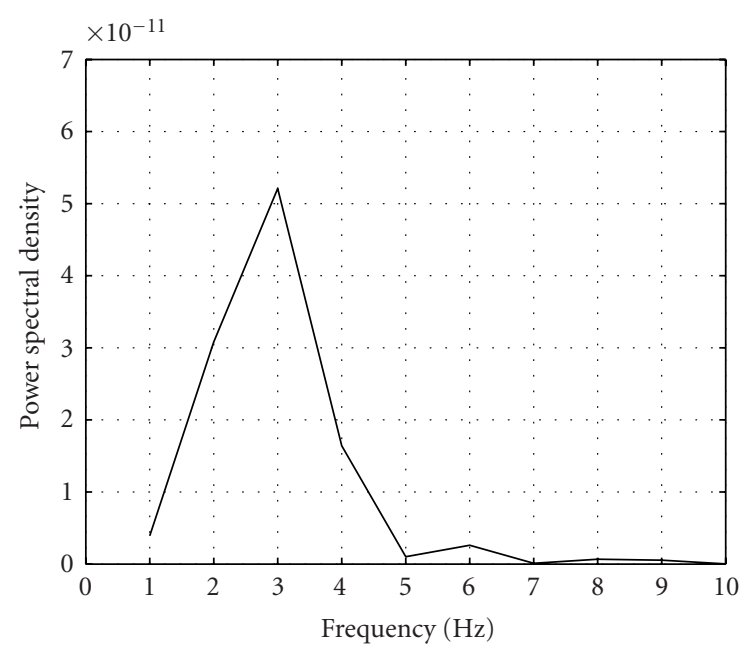

FIGURE 6. BDR subject VEP spectrum.

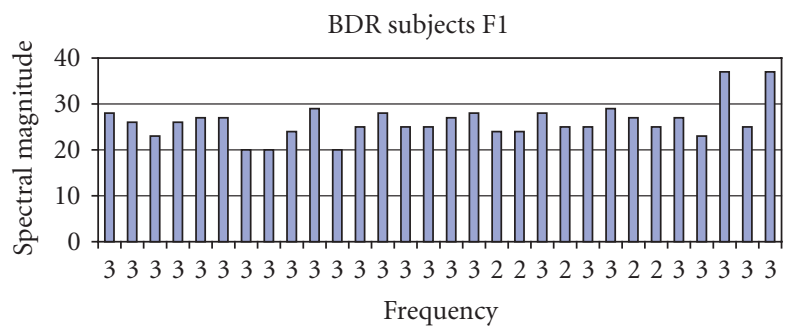

FIgURE 7. 30 BDR patients' first spectral component 2D histogram.

It is shown that the dominant spectral component falls at $3 \mathrm{~Hz}$ and the secondary component at $6 \mathrm{~Hz}$. $30 \mathrm{BDR}$ subjects' dominant spectral component magnitudes 2D histogram is presented in Figure 7 and the corresponding second dominant peak magnitude values are presented in Figure 8.

For PPDR subjects we found that the dominant spectral peak falls in the range of $4-6 \mathrm{~Hz}$ and the second dominant peak falls at $2 \mathrm{~Hz}$ or in the range of $6-10 \mathrm{~Hz}(P<$ .001 ). Figure 9 shows the spectral plot of PPDR subject. It is shown that the dominant spectral component falls at

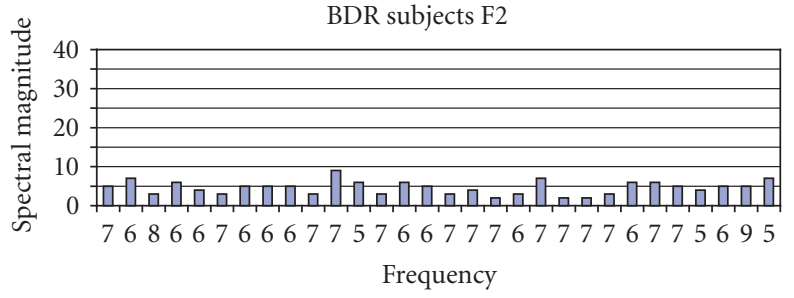

FIGURE 8. 30 BDR patients' second spectral component 2D histogram.

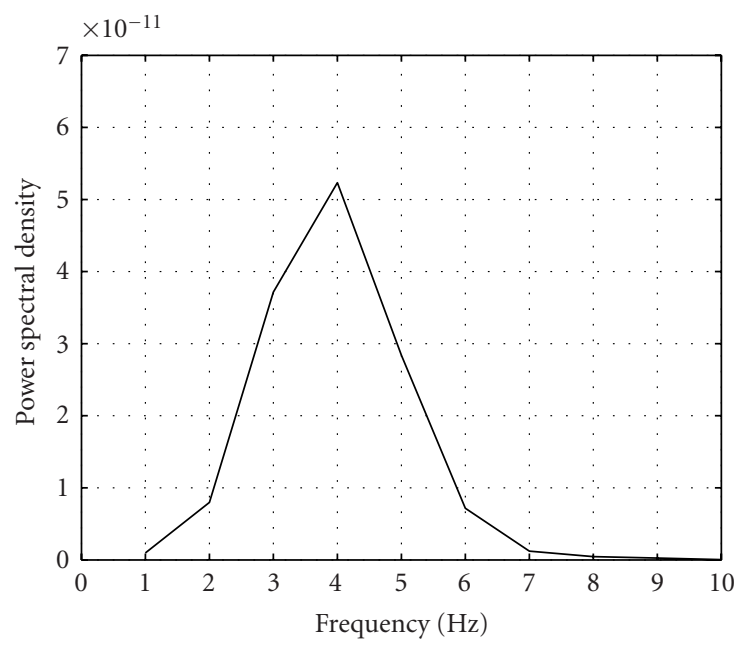

FIGURE 9. PPDR subject VEP spectrum.

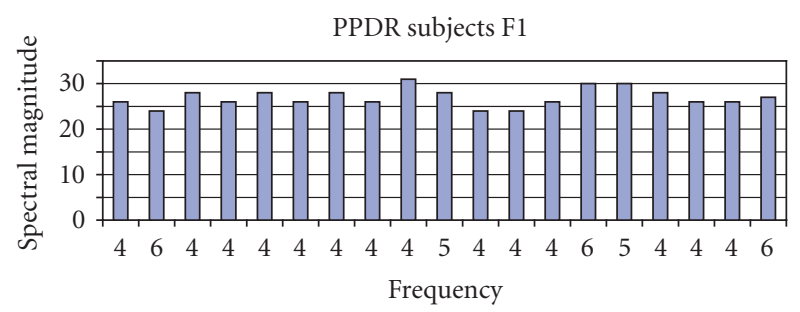

FIgURE 10. 20 PPDR patients' first spectral component 2D histogram.

$4 \mathrm{~Hz}$ and no secondary component exists. 20 PPDR subjects' dominant spectral component magnitudes 2D histogram is presented in Figure 10 and the corresponding second dominant peak magnitude values are presented in Figure 11.

For PDR subjects we found that the dominant spectral peak falls in the range of $6-8 \mathrm{~Hz}$ and the second dominant peak falls in the range of $2-3 \mathrm{~Hz}(P<.001)$. Figure 12 shows the spectral plot of PDR subject. It is shown that the dominant spectral component falls at $6 \mathrm{~Hz}$ and no secondary component exists. 20 PDR subjects' dominant spectral component magnitudes $2 \mathrm{D}$ histogram are presented in Figure 13 and the corresponding second dominant peak magnitude values are presented in Figure 14. 


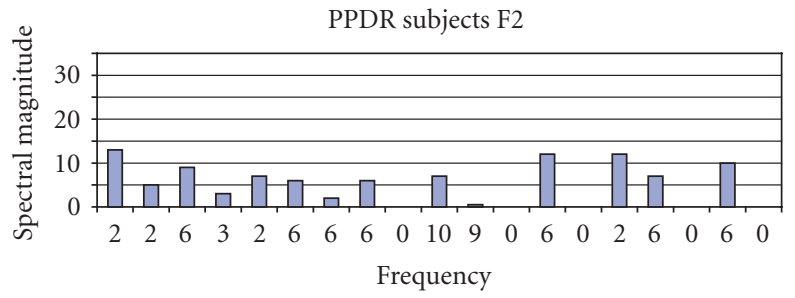

FIgURE 11. 20 PPDR patients' second spectral component 2D histogram.

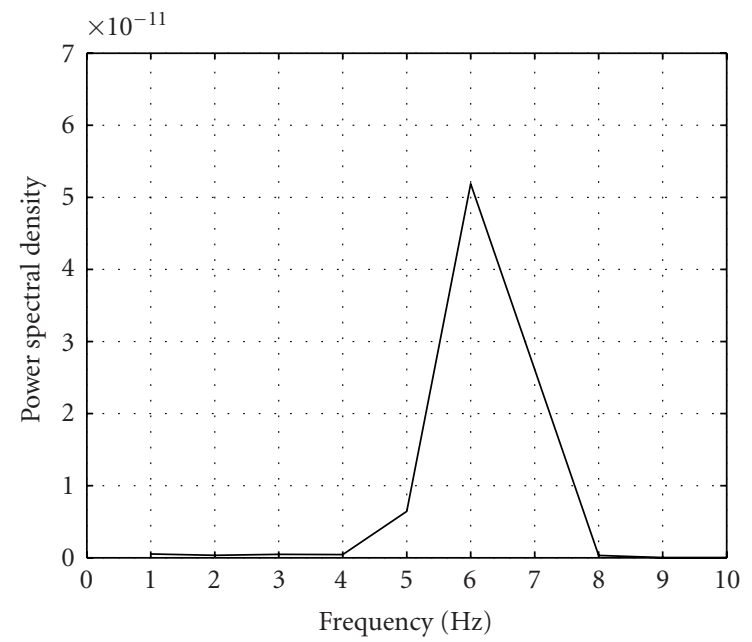

FIgURE 12. PDR subject VEP spectrum.

\section{Neural network interpretation of VEP data}

The classification ANN was trained on 25 normal and 200 abnormal subjects, that is, BDR, PPDR, and PDR subjects VEP spectral components, and tested on 25 normal subjects and 100 diabetic subjects VEP spectral components. We found that $95 \%$ of VEPs were classified correctly.

We animated the diabetic retinopathy condition using 3D Max Studio and Windows Movie Maker from the hospital database and correlated with the VEP spectral components. We added voice information along with the picture information, which correlated the VEP wave with stages of diabetic retinopathy and treatment method. Using this animation the patient can identify the change in VEP and change in retinal condition. Users were able to explore the eye components to discover retinopathy characteristics. This animation and simulation model will eventually be used to educate patients and medical students on various aspects of the diabetic retinopathy (Figures 15 and 16).

\section{DISCUSSION}

A system for classification of diabetic retinopathy using VEP spectral components has been developed

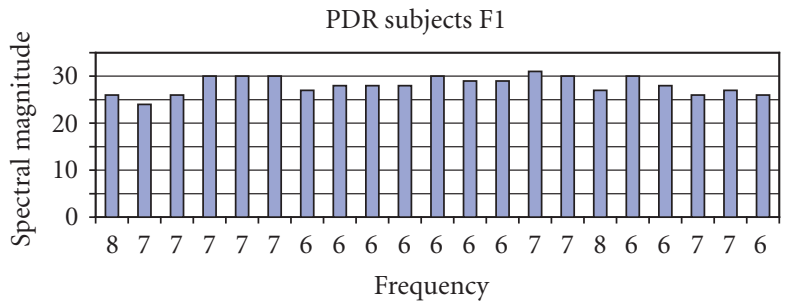

FIgURE 13. 20 PDR patients' first spectral component 2D histogram.

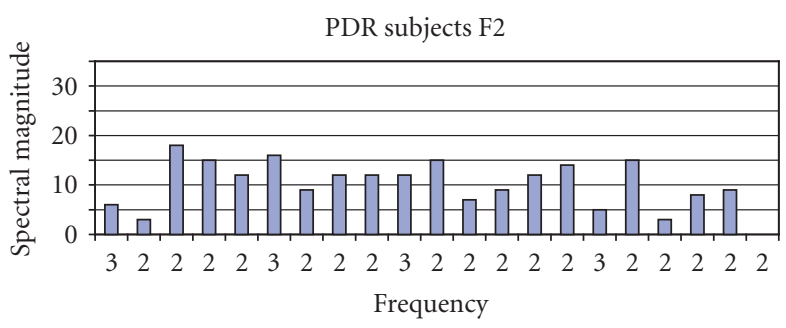

FIGURE 14. 20 PDR patients' second spectral component 2D histogram.

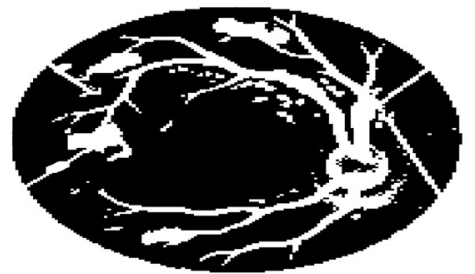

FIgURE 15. Animated retinal blood vessel picture.

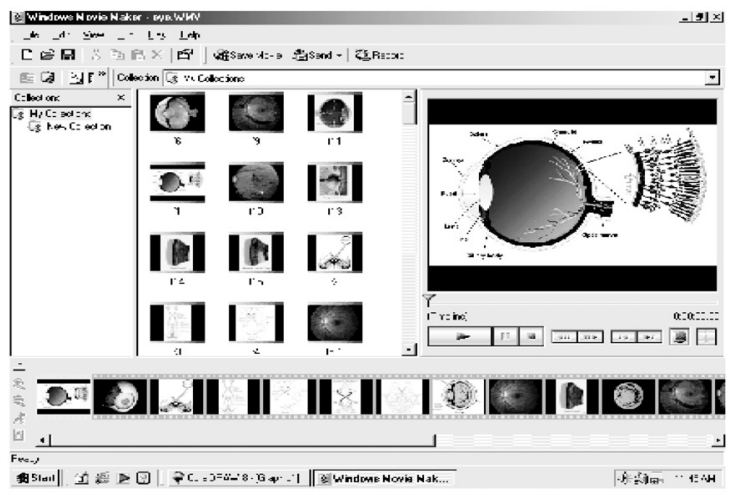

FIgURe 16. Animated diabetic retinopathy movie.

and tested on prerecorded data from a set of patients. This paper describes a specific application which can be extended to further applications in medicine. 
Presently we are testing the system on a large patient offline database and in the future it can be implemented for routine clinical use. This method of classification of diabetic retinopathy condition using frequency spectrum and peak frequency components almost coincides with the expected retinopathy condition. These results will have significant usage in analyzing the diabetic retinopathy condition. This system provides an early warning of diabetic retinopathy abnormalities for diabetic patients.

\section{ACKNOWLEDGMENT}

The data used in this work were obtained from the Sri Ramachandra Medical College and Research Institute (Deemed university), India.

\section{REFERENCES}

[1] Chen MS, Kao CS, Fu CC, Chen CJ, Tai TY. Incidence and progression of diabetic retinopathy among non-insulin-dependent diabetic subjects: a 4-year follow-up. Int J Epidemiol. 1995;24(4):787795.

[2] El-Asrar AM, Al-Rubeaan KA, Al-Amro SA, Kangave D, Moharram OA. Risk factors for diabetic retinopathy among Saudi diabetics. Int Ophthalmol. 19981999;22(3):155-161.

[3] Maberley DA, King W, Cruess AF, Koushik A. Risk factors for diabetic retinopathy in the Cree of James Bay. Ophthalmic Epidemiol. 2002;9(3):153-167.

[4] Araki A, Ito H, Hattori A, et al. Risk factors for development of retinopathy in elderly Japanese patients with diabetes mellitus. Diabetes Care. 1993;16(8):1184-1186.

[5] Larsson LI, Alm A, Bergenheim T, Lithner F, Bergstrom R. Retinopathy in diabetic patients aged 15-50 years in the county of Umea, Sweden. Acta Ophthalmol Scand. 1999;77(4):430-436.

[6] Harris EL, Sherman SH, Georgopoulos A. Blackwhite differences in risk of developing retinopathy among individuals with type 2 diabetes. Diabetes Care. 1999;22(5):779-783.

[7] Kim HK, Kim CH, Kim SW, et al. Development and progression of diabetic retinopathy in Koreans with NIDDM. Diabetes Care. 1998;21(1):134-138.

[8] Rasmidatta S, Khunsuk-Mengrai K, Warunyuwong C. Risk factors of diabetic retinopathy in noninsulin dependent diabetes mellitus. J Med Assoc Thai. 1998;81(3):169-174.

[9] Amos AF, McCarty DJ, Zimmet P. The rising global burden of diabetes and its complications: estimates and projections to the year 2010. Diabet Med. 1997;14 (suppl 5):S1-S85.

[10] Public health focus: prevention of blindness associated with diabetic retinopathy. MMWR Morb Mortal Wkly Rep. 1993;42(10):191-195.
[11] Wolfensberger TJ, Hamilton PAM. Diabetic retinopathy-a historical review. Semin Ophthalmol. 2001;16(1):2-7.

[12] Cohen O, Norymberg K, Neumann E, Dekel H. Complication-free duration and the risk of development of retinopathy in elderly diabetic patients. Arch Intern Med. 1998;158(6):641-644.

[13] Comi G. Evoked potentials in diabetes mellitus. Clin Neurosci. 1997;4(6):374-379.

[14] Nathan DM. Prevention of long-term complications of non-insulin-dependent diabetes mellitus. Clin Invest Med. 1995;18(4):332-339.

[15] Ryan CM, Geckle M. Why is learning and memory dysfunction in type 2 diabetes limited to older adults? Diabetes Metab Res Rev. 2000;16(5):308-315.

[16] Salem M, Ajlouni, K. Diabetic retinopathy among Jordanians: its pattern, severity, and some associated risk factors. Diabetol Croat. 1999;28(1):17-23.

[17] Moreo G, Mariani E, Pizzamiglio G, Colucci GB. Visual evoked potentials in NIDDM: a longitudinal study. Diabetologia. 1995;38(5):573-576.

[18] Kohner EM, Aldington SJ, Stratton IM, et al. United Kingdom prospective diabetes study, 30: diabetic retinopathy at diagnosis of non-insulin-dependent diabetes mellitus and associated risk factors. Arch Ophthalmol. 1998;116(3):297-303.

[19] Verrotti A, Trotta D, Matera V, Giuva T, Chiarelli F. Visual evoked potential in newly diagnosed diabetic children. Diabetes Res Clin Pract. 1999;44(suppl 1):S34.

[20] Stojkovic T, de Seze J, Hurtevent JF, et al. Visual evoked potential study in chronic inflammatory demyelinating polyneuropathy. In: Electrophysiological Studies in Neuropathy. San Diego, Calif; July, 1999.

[21] Ikejiri M, Adachi-Usami E, Mizota A, Tsuyama Y, Miyauchi O, Suehiro S. Pattern visual evoked potentials in traumatic optic neuropathy. Ophthalmologica. 2002;216(6):415-419.

[22] Dasey TJ, Micheli-Tzanakou E. Detection of multiple sclerosis with visual evoked potentials - an unsupervised computational intelligence system. IEEE Trans Inf Technol Biomed. 2000;4(3):216-224.

[23] Pan $\mathrm{CH}$, Chen SS. Pattern shift visual evoked potentials in diabetes mellitus. Gaoxiong Yi Xue Ke Xue Za Zhi. 1992;8(7):374-383.

[24] Millingen KS, Yeo PT, Kamaldeen S. Visual evoked responses in diabetes. Clin Exp Neurol. 1987;24:153158.

[25] Aguggia M, Baruchello M, Dimanico U, Filippi P, Gilli M, Riccio A. Correlated study of visual evoked potentials-polyneuropathy in diabetic patients without retinopathy. Minerva Med. 1993;84(5):227-231.

[26] Nedzvetskaia OV, Chumak SA. Clinical and functional characteristics of changes in the optic nerve in juvenile diabetic retinopathy. Ann Ophthalmol. 2001;117(3):7-11. 
[27] Cirillo D, Gonfiantini E, De Grandis D, Bongiovanni L, Robert JJ, Pinelli L. Visual evoked potentials in diabetic children and adolescents. Diabetes Care. 1984;7(3):273-275.

[28] Puvanendran K, Devathasan G, Wong PK. Visual evoked responses in diabetes. I Neurol Neurosurg Psychiatry. 1983;46(7):643-647.

[29] Algan M, Ziegler O, Gehin P, et al. Visual evoked potentials in diabetic patients. Diabetes Care. 1989;12(3):227-229.

[30] Yaltkaya K, Balkan S, Baysal AI. Visual evoked potentials in diabetes mellitus. Acta Neurol Scand. 1988;77(3):239-241.

[31] Parisi V, Uccioli L, Monticone G, Parisi L, Menzinger G, Bucci MG. Visual evoked potentials after photostress in insulin-dependent diabetic patients with or without retinopathy. Graefes Arch Clin Exp Ophthalmol. 1994;232(4):193-198.

[32] Ponte F, Giuffre G, Anastasi M, Lauricella M. Involvment of the visual evoked potentials in type I insulin-dependent diabetes. Metab Pediatr Syst Ophthalmol. 1986;9(2-4):77-80.

[33] Fierro B, Meli F, Brighina F, et al. Somatosensory and visual evoked potentials study in young insulindependent diabetic patients. Electromyogr Clin Neurophysiol. 1996;36(8):481-486.

[34] Verrotti A, Lobefalo L, Trotta D, et al. Visual evoked potentials in young persons with newly diagnosed diabetes: a long-term follow-up. Dev Med Child Neurol. 2000;42(4):240-244.

[35] Parisi V, Uccioli L, Parisi L, et al. Neural conduction in visual pathways in newly-diagnosed IDDM patients. Electroencephalogr Clin Neurophysiol. 1998;108(5):490-496.

[36] Seidl R, Birnbacher R, Hauser E, Bernert G, Freilinger M, Schober E. Brainstem auditory evoked potentials and visually evoked potentials in young patients with IDDM. Diabetes Care. 1996;19(11): 1220-1224.

[37] Comi G, Martinelli V, Galardi G, et al. Visual evoked potentials in diabetic teen-agers: influence of metabolic control and relationship with peripheral neuropathy. Metab Pediatr Syst Ophthalmol. 1986;9(2-4):85-87.

[38] Alessandrini M, Paris V, Bruno E, Giacomini PG. Impaired saccadic eye movement in diabetic patients: the relationship with visual pathways function. Doc Ophthalmol. 1999;99(1):11-20.

[39] Abe H, Hasegawa S, Takagi M, Yoshizawa T, Usui T. Temporal modulation transfer function of vision by pattern visual evoked potentials in patients with optic neuritis. Ophthalmologica. 1993;207(2):94-99.

[40] Palaniappan R, Raveendran P. Recursive digital filter for fast visual evoked potential estimation and classification. Electronics Letters. 2001;37(15):990-992.

[41] Davila CE, Abaye A, Khotanzad A. Adaptive line enhancement of steady-state visual evoked potentials. In: IEEE Proceedings of the 12th Southern Biomedical
Engineering Conference. New Orleans, La, USA; April 1993:283-285.

[42] Fung KSM, Chan FHY, Lam FK, Poon PWF, Liu JG. Visual evoked potential estimation by artificial neural network filter: comparison with the ensemble averaging method. In: Proceedings of the IEEE 17th Annual Conference Engineering in Medicine and Biology Society. vol. 1. Montreal, Quebec, Canada; September, 1995:805-806.

[43] Fung KSM, Lam FK, Chan FHY, Poon PWF, Lin JG. Adaptive neural network filter for visual evoked potential estimation. In: Proceedings of the IEEE International Conference on Neural Networks. vol. 5. Perth, WA, Australia; November-December, 1995:2293-2296.

[44] Fotopoulos S, Economou G, Bezerianos A, Laskaris N. Latency measurement improvement of P100 complex in visual evoked potentials by FMH filters. IEEE Trans Biomed Eng. 1995;42(4):424-428.

[45] Aunon JI. Evoked potentials research. IEEE Eng Med Biol Mag. 1992;11(1):67-68.

[46] Kong X, Qiu T. Latency change estimation for evoked potentials via frequency selective adaptive phase spectrum analyzer. IEEE Trans Biomed Eng. 1999;46(8):1004-1012.

[47] Gulcur HO, Demirer M, Demiralp T. An RBF approach to single trial VEP estimation. In: Proceedings of the 1998 2nd International Conference Biomedical Engineering Days. Istanbul, Turkey; May, 1998:5456.

[48] Micheli-Tzanakou E, Pavlopoulos S. Analysis of VEP using phase information. In: Proceedings of the 10th Annual International Conference of the IEEE Engineering in Medicine and Biology Society (EMBS '88). New Orleans, La, USA; 1988:1160-1161.

[49] Pecher A, Husar P, Henning G, Roderer H. Phase estimation of visual evoked responses. IEEE Trans Biomed Eng. 2003;50(3):324-333.

[50] Moody EB, Micheli-Tzanakou E, Chokroverty S. An adaptive approach to spectral analysis of patternreversal visual potentials. IEEE Trans Biomed Eng. 1989;36(4):439-447.

[51] Kramarenko AV, Tan U. Validity of spectral analysis of evoked potentials in brain research. Int J Neurosci. 2002;112(4):489-499.

[52] Sivakumar R, Ravindran G. Visual evoked potential spectral component analysis. In: 2nd European Medical \& Biological Engineering Conference (EM$B E C$ '02). Vienna, Austria; December, 2002:18-20.

[53] Skuse NF, Burke D. Power spectrum and optimal filtering for visual evoked potentials to pattern reversal. Electroencephalogr Clin Neurophysiol. 1990;77(3):199-204.

[54] Marrelli A, Tozzi E, Porto C, Cimini N, Aloisi P, Valenti M. Spectral analysis of visual potentials evoked by pattern-reversal checkerboard in juvenile patients with headache. Headache. 2001;41(8):792797. 
[55] Schurmann M, Basar-Eroglu C, Basar E. Auditory and visual evoked potentials: topographic and modality-dependent differences in the frequency domain. In: Proceedings of the IEEE Engineering in Medicine and Biology Society. vol. 13. October, 1991:397-398.

[56] Davila CE, Srebro R, Ghaleb IA. Optimal detection of visual evoked potentials. IEEE Trans Biomed Eng. 1998;45(6):800-803.

[57] Demiralp T, Ademoglu A, Dulger H, Gulcur HO. Prestimulus EEG classification by means of parametric methods to characterize evoked potential variabilities. In: Proceedings of the IEEE International Biomedical Engineering Days. Istanbul, Turkey; August, 1992:151-156.

[58] Kulkarni GR, Udpikar V. An integrated facility for data acquisition and analysis of biomedical signals. Case studies on VEP, IVS. In: IEEE Proceedings of the 1st Regional Conference Engineering in Medicine and Biology Society, and 14th Conference of the Biomedical Engineering Society of India. New Delhi, India; February, 1995:3/67-3/68.

[59] Hasegawa S, Abe H. Maximum entropy method and Fourier transform for wave analysis of pattern visual evoked potentials. Nippon Ganka Gakkai Zasshi. 1992;96(3):400-407.

[60] Johansson B, Jakobsson P. Fourier analysis of steadystate visual evoked potentials in subjects with normal and defective stereo vision. Doc Ophthalmol. 2000;101(3):233-246.

[61] Nguyen HT, Butler M, Roychoudhry A, Shannon AG, Flack J, Mitchell P. Classification of diabetic retinopathy using neural networks. In: Proceedings of the 18th Annual International Conference of the IEEE Engineering in Medicine and Biology Society, Bridging Disciplines for Biomedicine. vol. 4. Amsterdam, The Netherlands; October-November, 1996:1548-1549.

[62] Casi E, Ceravola A, Cionini R, Sperduti A, Starita A, Viti S. Diabetic retina analyser. In: Proceedings of the 18th Annual International Conference of the IEEE Engineering in Medicine and Biology Society, Bridging Disciplines for Biomedicine. vol. 3. Amsterdam, The Netherlands; October-November, 1996:1128-1129.

[63] Sivakumar R, Ravindran G. Animation and simulation of eye in diabetic retinopathy. In: Proceedings of the 23rd Annual Conference of the Indian Association of Biomedical Scientists (IABMS '02). Pondicherry, India; October, 2002:42.

[64] Zahlmann G, Wilson S, Micheli-Tzanakou E. A knowledge based neural network classifier for visual evoked potentials. In: Proceedings of the Annual International Conference of the IEEE Engineering in Medicine and Biology Society. vol. 13. OctoberNovember, 1991:1345-1346.

[65] Iezzi Jr R, Micheli-Tzanakou E. 2-D spatial frequency dependence of VEPs: A neural network analysis. In: Proceedings of the 1993 19th Annual North- east of the IEEE Bioengineering Conference. March, 1993:111-112.

[66] Micheli-Tzanakou E. Biomedical applications of parallel processing and artificial neural networks. In: Proceedings of the International Biomedical Engineering Days. Istanbul, Turkey; August, 1992:10-17.

[67] Sivakumar R, Ravindran G. Using feed forward neural network to monitor mental state from changes in EEG spectral components. J Biomed Tech. 2001;4(5):4.

[68] Sivakumar R, Ravindran G. Using feed forward neural network to discriminate abnormal subjects using the visual evoked potential spectral components. In: Proceedings of the 6th International Conference on Cognitive and Neural Systems (CNS '02). May-June, 2002:6.

[69] Micheli-Tzanakou E. Applications of neural networks in biomedical engineering. In: Proceedings of the 1990 IEEE Colloquium in South America. Argentina, Brazil, Chile, Uruguay; August-September, 1990:7-12.

[70] Sgro JA, Emerson RG, Stanton PC. Automated evoked potential analysis using backpropagation networks. In: Proceedings of the IEEE World Congress on Computational Intelligence, International Joint Conference on Neural Networks. vol. 1. Anchorage, Alaska, USA; May, 1998:123-127.

[71] Suaste E, Rivera P, Leybon J, et al. 3D visualization, simulation, animation and modeling of eyepupil movements and visual field for clinical applications. In: Proceedings of the 18th Annual International Conference of the IEEE Engineering in Medicine and Biology Society, Bridging Disciplines for Biomedicine. vol. 5. Amsterdam, The Netherlands; October-November, 1996:2277-2278.

* Corresponding author.

E-mail: sivarkumar@mailcity.com

Fax: +91 422 2678012; Tel: +91 442351723 


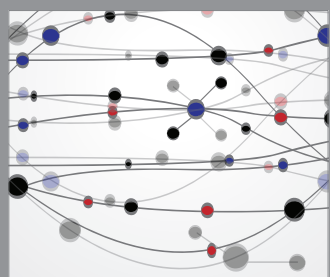

The Scientific World Journal
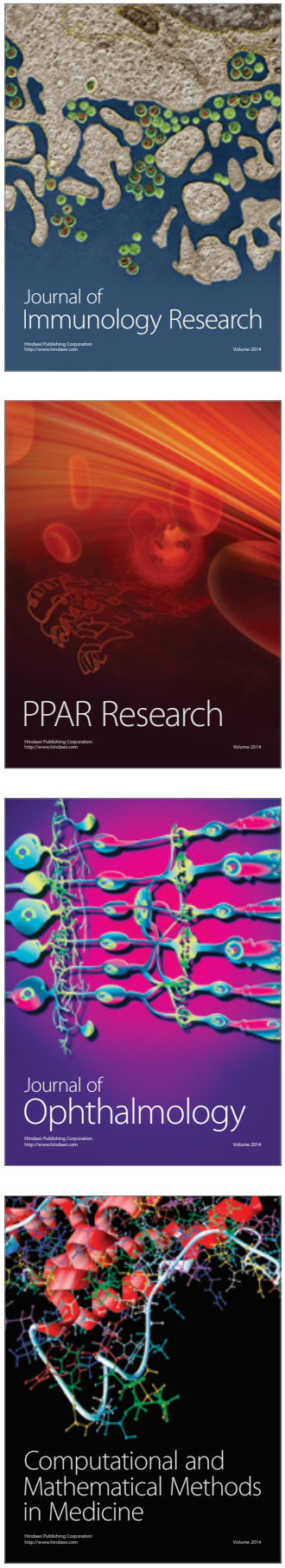

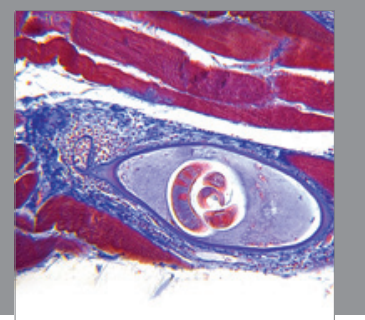

Gastroenterology

Research and Practice
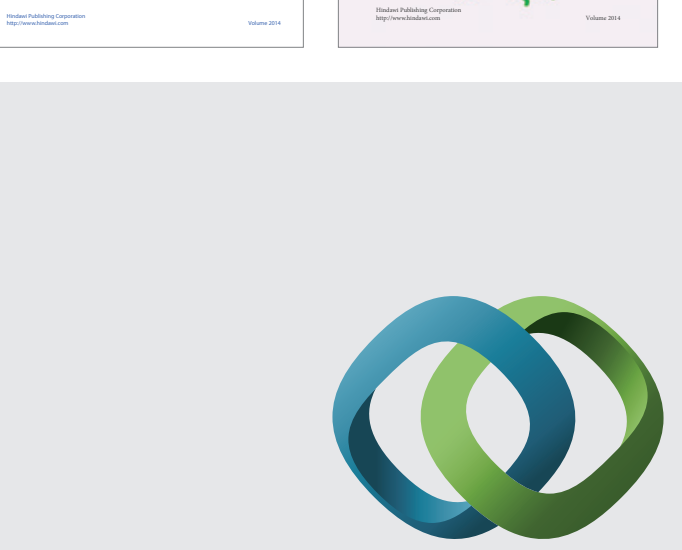

\section{Hindawi}

Submit your manuscripts at

http://www.hindawi.com
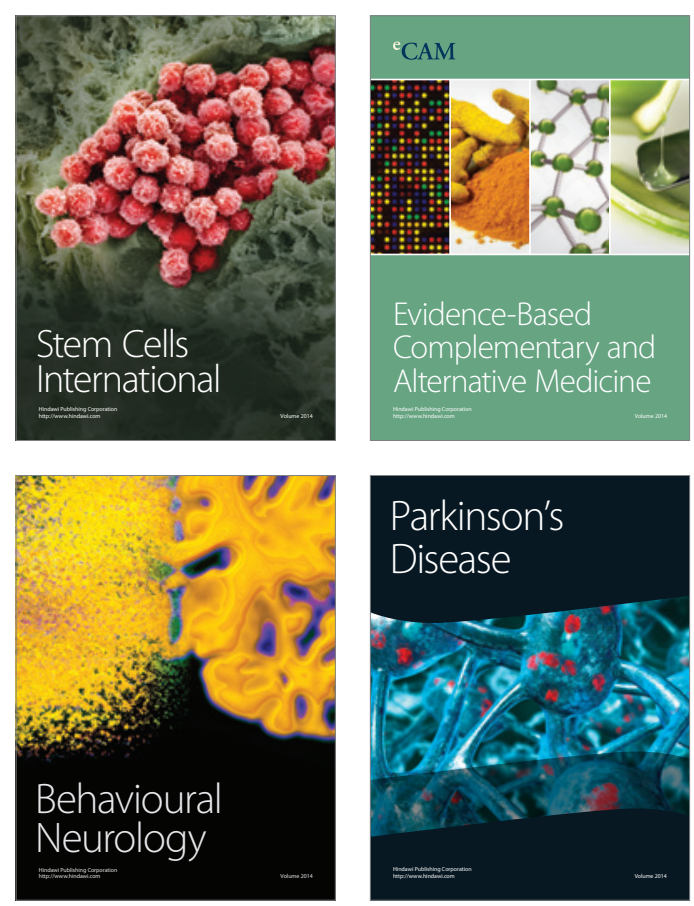

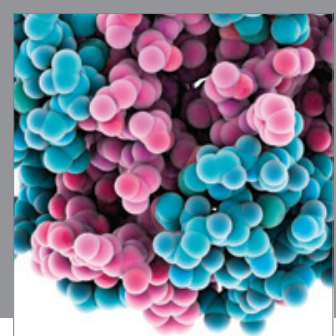

Journal of
Diabetes Research

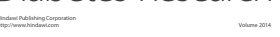

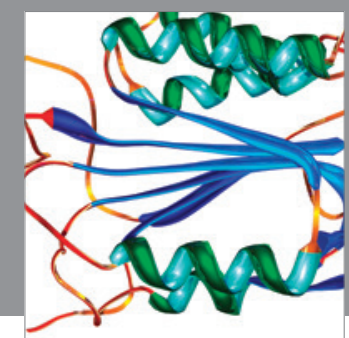

Disease Markers
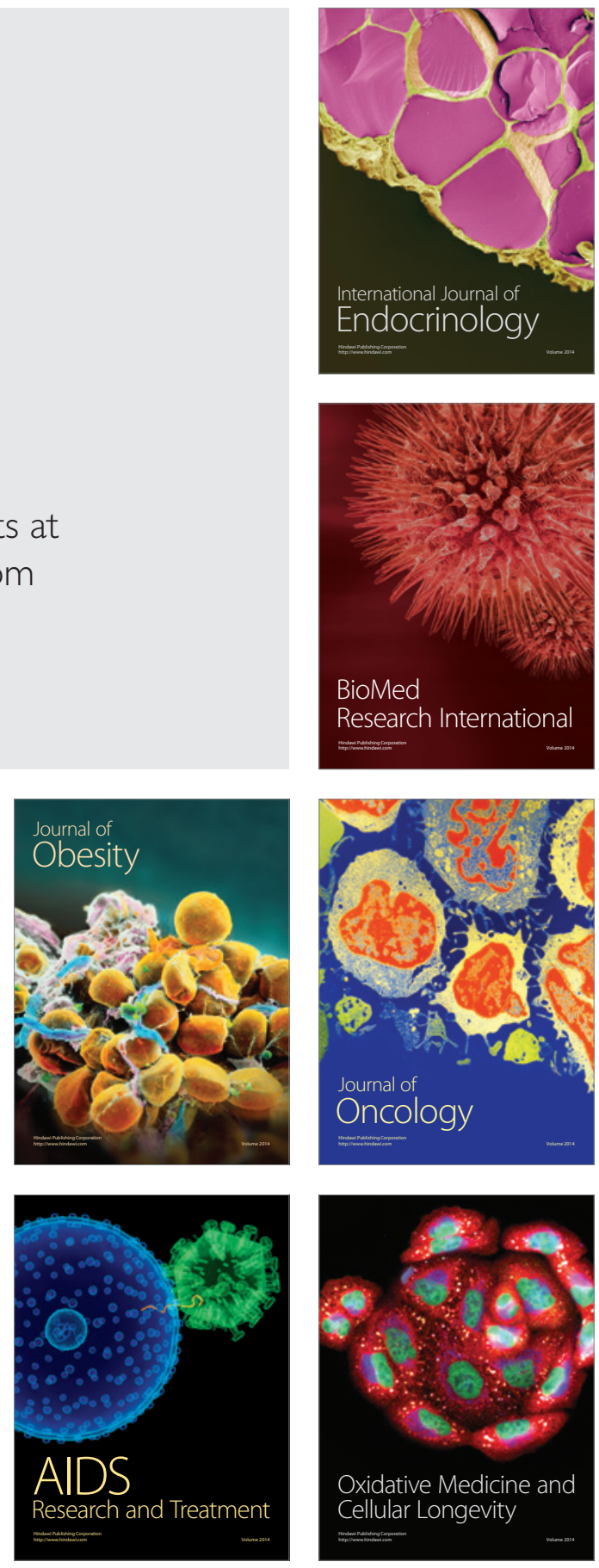